\title{
Density functional theory investigation of the electronic structure and defect chemistry of $\mathrm{Sr}_{1-x} \mathrm{~K}_{x} \mathrm{FeO}_{3}$
}

\begin{abstract}
Andrew M. Ritzmann, Department of Chemical and Biological Engineering, Princeton University, Princeton, NJ 08540, USA† Johannes M. Dieterich, Department of Mechanical and Aerospace Engineering, Princeton University, Princeton, NJ 08540, USA Emily A. Carter, Department of Mechanical and Aerospace Engineering, Program in Applied and Computational Mathematics, Andlinger Center for Energy and the Environment, Princeton University, Princeton, NJ 08540, USA
\end{abstract}

Address all correspondence to Emily A. Carter at eac@princeton.edu

(Received 26 May 2016; accepted 18 July 2016)

\section{Abstract}

Solid oxide fuel cells (SOFCs) efficiently generate electricity, but high operating temperatures $\left(T_{\mathrm{op}}>800{ }^{\circ} \mathrm{C}\right)$ limit their utility. Reducing $T_{\mathrm{op}}$ requires mixed ion-electron conducting (MIEC) cathode materials. Density functional theory is used here to investigate the role of potassium substitutions in the MIEC material $\mathrm{Sr}_{1-x} \mathrm{~K}_{x} \mathrm{FeO}_{3}$ (SKFO). We predict that such substitutions are endothermic. SrFeO $\mathrm{O}_{3}$ and $\mathrm{SKFO}$ have nearly identical metallic electronic structures. Oxygen vacancy formation energies decrease by $\sim 0.2 \mathrm{eV}$ when $x_{\mathrm{K}}$ increases from 0 to 0.0625 . SKFO is a promising SOFC MIEC cathode material; however, further experimental investigations must assess its long-term stability at the desired operating temperatures.

Solid oxide fuel cells (SOFCs) provide a clean and efficient means of generating electrical power from various fuel sources. ${ }^{[1]}$ However, high operating temperatures $\left(T_{\text {op }}>800{ }^{\circ} \mathrm{C}\right) \mathrm{re}-$ duce the overpotential arising from standard $\mathrm{La}_{1-x} \mathrm{Sr}_{x} \mathrm{MnO}_{3}$ cathodes, but increase material costs and shorten cell life-

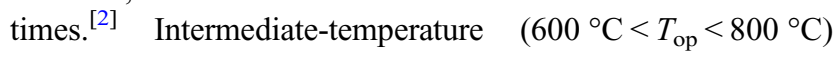
SOFCs have potential to overcome these deficiencies but in turn require alternative, mixed ion-electron conducting (MIEC) cathode materials to increase the active region and reduce the cathode overpotential. ${ }^{[3]}$ Useful MIEC cathode materials must allow for facile electronic and ionic conductivity.

$\mathrm{La}_{1-x} \mathrm{Sr}_{x} \mathrm{Co}_{1-y} \mathrm{Fe}_{y} \mathrm{O}_{3}$ remains the reference MIEC cathode ${ }^{[4-7]}$ although many other cathode materials show promising electrochemical behavior. These include $\mathrm{Ba}_{1-x} \mathrm{Sr}_{x} \mathrm{Co}_{1-y}$ $\mathrm{Fe}_{y} \mathrm{O}_{3}$ (BSCF), $\mathrm{Sr}_{2} \mathrm{Fe}_{2-x} \mathrm{Mo}_{x} \mathrm{O}_{6}$ (SFMO), and $\mathrm{Sr}_{1-x} \mathrm{~K}_{x} \mathrm{FeO}_{3}$ (SKFO) ${ }^{[8-10]}$ Many experimental studies have illuminated the structural properties, oxygen transport kinetics, and electrochemical performance of LSCF, BSCF, and SFMO ${ }^{[6,10-13]}$ Far less is known about SFKO. Hou et al. reported that cathodes of $\mathrm{Sr}_{0.9} \mathrm{~K}_{0.1} \mathrm{FeO}_{3}$ (with a $\mathrm{La}_{0.8} \mathrm{Sr}_{0.2} \mathrm{Ga}_{0.83} \mathrm{Mg}_{0.17} \mathrm{O}_{3-\delta}$, or LSGM, electrolyte and a $\mathrm{Sr}_{2} \mathrm{MgMoO}_{6}$ anode) produced a current density competitive with LSCF at $800^{\circ} \mathrm{C} .{ }^{[9]}$ Repetitive cycling of the cell between open circuit voltage and $0.4 \mathrm{~V}$ caused no loss in the observed power density. ${ }^{[9]}$ Furthermore, SFKO cathodes contain no $\mathrm{Co}$, which improves their cost-effectiveness. ${ }^{[14]}$

A previous error in this article's header has been corrected.

$\dagger$ Permanent address: The Pennington School, 112 W. Delaware Avenue, Pennington, NJ 08534, USA.
Additional studies support the use of $\mathrm{Sr}_{0.9} \mathrm{~K}_{0.1} \mathrm{FeO}_{3}$ as a SOFC cathode material by offering additional evidence of its stability $^{[15]}$ and demonstrating a viable synthesis method for the material. ${ }^{[16]}$

The small body of experimental evidence supporting SKFO as an MIEC cathode in SOFC applications suggests that further investigation into this material is warranted. ${ }^{[9,15,16]}$ Firstprinciples quantum mechanics methods based on KohnSham density functional theory (KS-DFT) have proven useful in providing rational design principles for related materials. ${ }^{[17-26]}$ Here we provide a DFT study of SKFO $\left(x_{\mathrm{K}}=0\right.$, 0.0625 , and 0.125 ) aimed at answering three questions. First, does potassium substitution $\left(\mathrm{K}_{\mathrm{Sr}}^{/}\right.$in Kröger-Vink notation ${ }^{[27]}$ ) negatively impact the stability of SKFO? Second, how does the presence of $\mathrm{K}_{\mathrm{Sr}}^{\prime}$ substitutions cause the electronic structure of SKFO to differ from that of $\mathrm{SrFeO}_{3}$ ? Finally, do the holes introduced by $\mathrm{K}_{\mathrm{Sr}}^{\prime}$ defects lead to lower oxygen vacancy $\left(\mathrm{V}_{\mathrm{O}}^{\bullet \bullet}\right.$ in Kröger-Vink notation $\left.{ }^{[27]}\right)$ formation energies and, thus, higher oxygen vacancy concentrations?

We address the preceding questions, focusing on the similarities and differences between compositions. This investigation provides fundamental understanding of the effects governing how electron-deficient substitutions in $\mathrm{SrFeO}_{3}-$ based materials influence their performance as MIEC cathodes.

Our KS-DFT calculations of SKFO $\left(x_{\mathrm{K}}=0,0.0625\right.$, and $0.125)$ were performed using the Vienna $a b$ initio Simulation Package (VASP) version 5.2.2. ${ }^{[28]}$ Electron exchange and correlation was treated within the generalized gradient approximation (GGA) of Perdew et al. ${ }^{[29]}$ The 80 -atom supercell shown in 


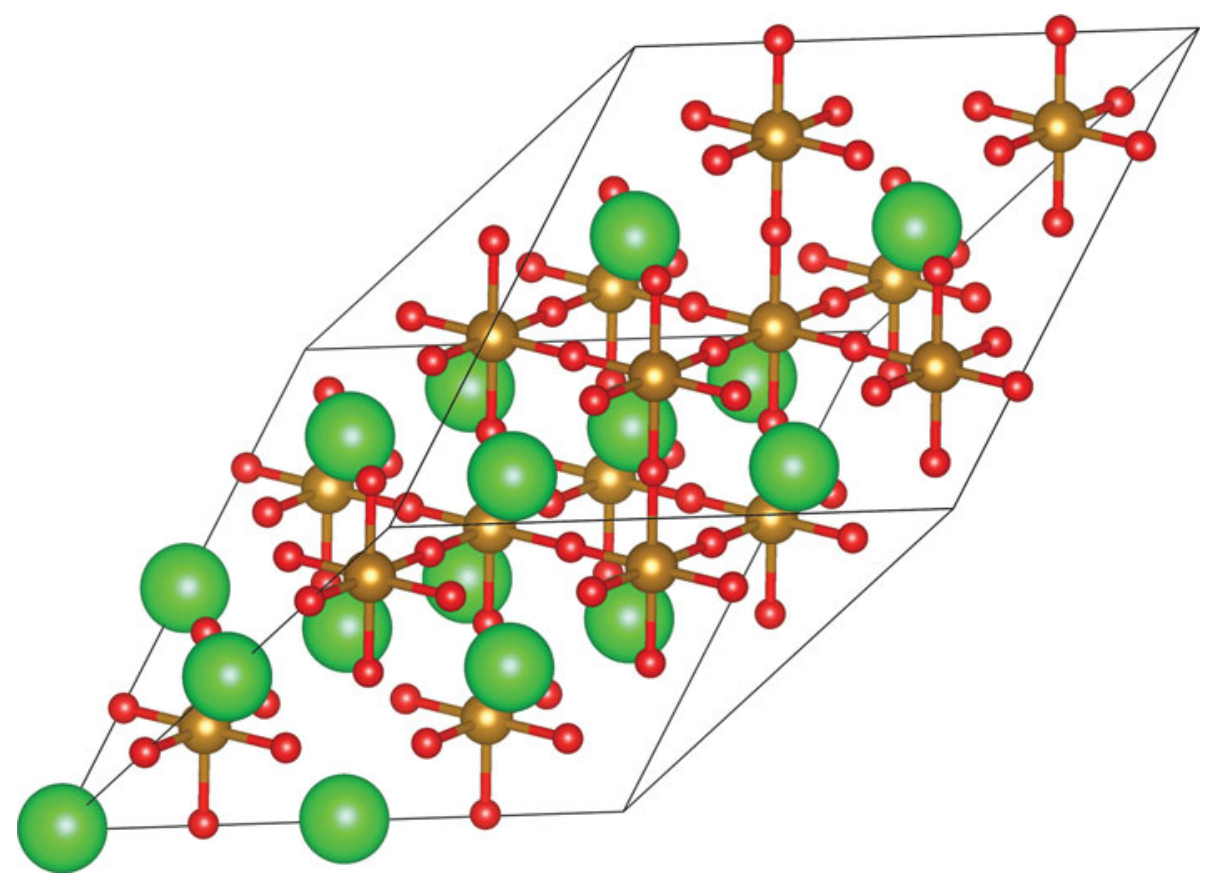

Figure 1. The 80-atom supercell of $\mathrm{SrFeO}_{3}$ employed here; large green spheres represent $\mathrm{Sr}$ atoms, medium gold spheres Fe atoms, and small red spheres oxygen atoms. This supercell was constructed from the primitive perovskite unit cell $\left(a_{\mathrm{p}}, b_{\mathrm{p}}, c_{\mathrm{p}}\right)$ with the following lattice vectors $\left(a_{\mathrm{s}}, b_{\mathrm{s}}, c_{\mathrm{s}}\right): a_{\mathrm{s}}=2 a_{\mathrm{p}}+2 b_{\mathrm{p}}, b_{\mathrm{s}}=$ $2 a_{\mathrm{p}}+2 c_{\mathrm{p}}$, and $c_{\mathrm{s}}=2 b_{\mathrm{p}}+2 c_{\mathrm{p}}$. This figure was created using VESTA. ${ }^{[30]}$

Fig. 1 was employed for all of the calculations reported. Our total energies are converged to $5 \mathrm{meV} /$ formula unit (full computational details are provided in the Supporting Information).

The stability of SKFO depends on the energy change associated with $\mathrm{K}_{\mathrm{Sr}}^{/}$substitutions. Although initial investigations indicate promising stability for this material, ${ }^{[9,15,16]}$ oxidizing $\mathrm{SrFeO}_{3}$ produces potentially unstable $\mathrm{Fe}^{4+}$ ions. Formal charge analysis suggests that highly unstable $\mathrm{Fe}^{5+}$ ions would also be formed as a result of $\mathrm{K}_{\mathrm{Sr}}^{\prime}$ substitutions; however, Mössbauer spectra of $\mathrm{Sr}_{0.9} \mathrm{~K}_{0.1} \mathrm{FeO}_{3}$ are completely explained with a mixture of $\mathrm{Fe}^{3+}$ and $\mathrm{Fe}^{4+}$ ions. ${ }^{[16]}$ Equation (1) presents the chemical process associated with $\mathrm{K}$ substitution, transforming $\mathrm{SrFeO}_{3}$ into SKFO. Equation (2) is used to calculate the energy change associated with forming $n \mathrm{~K}_{\mathrm{Sr}}^{\prime}$ substitutions $\left(\Delta E_{\mathrm{f}, \mathrm{K}_{\mathrm{Sr}}^{\prime}}\right)$.

$$
\mathrm{SrFeO}_{3}+n \mathrm{KO}_{2} \rightarrow \mathrm{Sr}_{1-x} \mathrm{~K}_{x} \mathrm{FeO}_{3}+n \mathrm{SrO}+\left(\frac{n}{2}\right) \mathrm{O}_{2}(\mathrm{~g}),
$$

$$
\Delta E_{\mathrm{f}, \mathrm{K}_{\mathrm{Sr}}^{\prime}}=\left(\frac{1}{n}\right)\left(E_{\mathrm{K} \text { present }}+n E_{\mathrm{SrO}}+\left(\frac{n}{2}\right) E_{\mathrm{O}_{2}}-E_{\mathrm{host}}-n E_{\mathrm{KO}_{2}}\right) .
$$

In Eq. (2), $n$ is the number of substitutional defects formed to create the appropriate composition $\left(x_{\mathrm{K}}\right)$ of SKFO in the 80 -atom supercell. We consider the $n=1$ case $\left(x_{\mathrm{K}}=0.0625\right)$ and the $n=2$ case $\left(x_{\mathrm{K}}=0.125\right)$. $\mathrm{SrO}$ (B1 structure) and $\mathrm{KO}_{2}$ are the most stable oxides for each of these cations (see Supporting Information), so these serve as the reference materials in Eq. (1). We calculate the cost per $\mathrm{K}_{\mathrm{Sr}}^{\prime}$ formed using Eq. (2). In this case, $E_{\mathrm{K} \text { present }}$ is the total energy of the 80-atom cell with one or two $\mathrm{K}_{\mathrm{Sr}}^{/}$defects present, $E_{\text {host }}$ is the total energy of $\mathrm{SrFeO}_{3}$ in the 80 -atom cell, $E_{\mathrm{O}_{2}}$ is the energy of the isolated oxygen molecule, $E_{\mathrm{SrO}}$ is the total energy per formula unit of $\mathrm{SrO}$ in its ground-state $\mathrm{B} 1(\mathrm{NaCl})$ structure, and $E_{\mathrm{KO}_{2}}$ is the total energy per formula unit of $\mathrm{KO}_{2}$.

The formation energies for $\mathrm{K}_{\mathrm{Sr}}^{\prime}$ are reported in Table I. Two key observations arise from the data presented: First, forming $\mathrm{K}_{\mathrm{Sr}}^{/}$defects is endothermic. Second, the formation energy per $\mathrm{K}_{\mathrm{Sr}}^{\prime}$ does not change for higher $x_{\mathrm{K}}$ or increased $\mathrm{K}_{\mathrm{Sr}}^{\prime}-\mathrm{K}_{\mathrm{Sr}}^{\prime}$ separation. The predicted endothermicity raises questions regarding the reported stability of the material. ${ }^{[9,15,16]}$ However, the calcination temperatures used to synthesize this material $(T=$ $\left.700-1100^{\circ} \mathrm{C}\right)^{[16]}$ will help stabilize the material as a result of the significant entropic contribution arising from the production of $\mathrm{O}_{2}$ gas in Eq. (1). The second observation indicates that there is no strong driving force for segregation or ordering of $\mathrm{K}_{\mathrm{Sr}}^{/}$defects. This result is consistent with the holes introduced by $\mathrm{K}_{\mathrm{Sr}}^{\prime}$ being highly delocalized (vide infra). We therefore expect that the true crystal will not show any ordering of $\mathrm{K}^{+}$and $\mathrm{Sr}^{2+}$ ions on the A-site sublattice.

The perovskite (cubic) phase is preferred when working with $\mathrm{SrFeO}_{3}$-based materials. However, the lattice may undergo a transition to a vacancy-ordered Brownmillerite phase that 

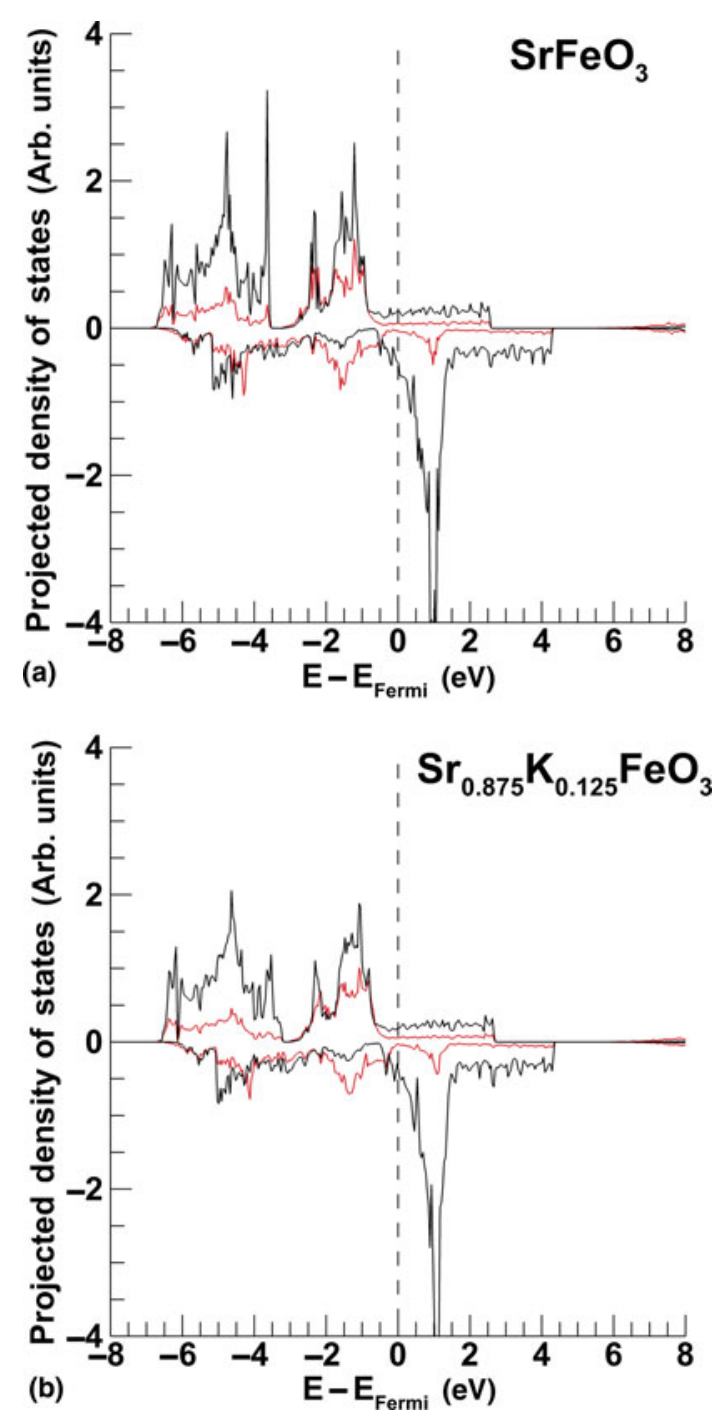

Figure 2. Projected densities of states (PDOS) for (a) $\mathrm{SrFeO}_{3}$ and (b) $\mathrm{Sr}_{0.875} \mathrm{~K}_{0.125} \mathrm{FeO}_{3}$ in the 80-atom supercell (Fig. 1). Color designations: Fe $3 d$ states (black) and $02 p$ states (red). By convention, positive (negative) PDOS refer to $\alpha(\beta)$-spin channels.

detrimentally impacts the material's electrical conductivity. We have been unsuccessful in obtaining a reliable optimized structure for the Brownmillerite phase with persistent, nonnegligible imaginary frequencies remaining after relaxation. Thus, we cannot currently comment on whether the phase equilibrium between the perovskite and Brownmillerite phases will be altered by the introduction of $\mathrm{K}_{\mathrm{Sr}}^{\prime}$ into the material.

In Fig. 2, we present the projected density of states (PDOS) for $\operatorname{SKFO}\left(x_{\mathrm{K}}=0\right.$ and 0.125$)$. Although $\mathrm{K}$ is present in these cells, the $4 s$ and $3 p$ states from the $\mathrm{K}$ atoms do not have a significant presence near the Fermi level. We therefore focus on the Fe $3 d$ and $\mathrm{O} 2 p$ states. When $x_{\mathrm{K}}=0.125$, we place the two $\mathrm{K}_{\mathrm{Sr}}^{\prime}$ defects on adjacent sites because the formation energy does not depend on the $\mathrm{K}_{\mathrm{Sr}}^{/}-\mathrm{K}_{\mathrm{Sr}}^{/}$separation (Table I).
Table I. Formation energies $\left(\Delta E_{\mathrm{f}, \mathrm{K}_{\mathrm{Sr}}^{\prime}}\right.$ in $\left.\mathrm{eV}\right)$ for $\mathrm{K}_{\mathrm{Sr}}^{\prime}$ substitutional defects at various concentrations $\left(X_{K}\right)$ and distances between defects $\left(d_{K-K}\right.$ in $\left.\AA\right)$. $\Delta E_{\mathrm{f}, \mathrm{K}_{\mathrm{Sr}}^{\prime}}$ values in parentheses include a correction of $+0.42 \mathrm{eV}$ for the overbinding of the $\mathrm{O}_{2}$ molecule in DFT-GGA calculations.

\begin{tabular}{lll}
\hline$x_{\mathrm{K}}$ & $d_{\mathrm{K}-\mathrm{K}}$ & $\Delta E_{\mathrm{f}, \mathrm{K}_{\mathrm{sr}}^{\prime}}$ \\
\hline 0.0625 & - & $1.14(1.56)$ \\
\hline 0.125 & 3.85 & $1.16(1.58)$ \\
\hline 0.125 & 5.44 & $1.17(1.59)$ \\
\hline 0.125 & 6.67 & $1.16(1.58)$ \\
\hline 0.125 & 7.70 & $1.16(1.58)$ \\
\hline
\end{tabular}

The PDOS contain the same features whether $\mathrm{K}$ is present or absent. Both compositions exhibit a pair of broad peaks in the $\alpha$-spin channel for the Fe $3 d$ states and a strong (mostly unoccupied) Fe $3 d$ peak in the $\beta$-spin channel beginning just below the Fermi level. This peak in the $\beta$-spin Fe $3 d$ states is the primary cause of the metallic conductivity in SKFO. We also observe that the significant hybridization between the $\mathrm{Fe} 3 d$ and $\mathrm{O}$ $2 p$ states remains when $\mathrm{K}$ is present. We therefore can see that the electronic structure of $\mathrm{SrFeO}_{3}$ is essentially preserved up to $12.5 \% \mathrm{~K}_{\mathrm{Sr}}^{\prime}$ on the A-site sublattice. The PDOS for $\mathrm{Sr}_{0.875}$ $\mathrm{K}_{0.125} \mathrm{FeO}_{3}$ confirms the metallic conductivity observed experimentally for SKFO above $350{ }^{\circ} \mathrm{C} .{ }^{[9,16]}$ We cannot evaluate the experimentalists' assertion that a polaronic mechanism governs electronic transport below this temperature.

We augment our analysis of the PDOS shown in Fig. 2 by presenting the Fe magnetic moments and Bader charges for all species (Table II) in the same cells and compositions. This process establishes how the $\mathrm{SrFeO}_{3}$ lattice responds to $\mathrm{K}_{\mathrm{Sr}}^{\prime}$ introduction. We find that both the $\mathrm{Fe}$ and $\mathrm{O}$ sublattices are oxidized in the presence of $\mathrm{K}_{\mathrm{Sr}}^{\prime}$. Specifically, we observe an increase in the positive Fe Bader charge of 0.02-0.03 e per site for each $\mathrm{K}$ atom added (moving right by one column in Table II). Likewise, we observe a decrease in the negative O Bader charge of 0.01-0.02 e per site. The lattice must find a way to accommodate each $\mathrm{K}_{\mathrm{Sr}}^{/}$that renders $0.78 e\left(q_{\mathrm{Sr}}-q_{\mathrm{K}}\right.$ in the third and fourth rows of data in Table II) no longer available to the lattice. The extent of each hole is obtained as the difference between the $\mathrm{Sr}$ and $\mathrm{K}$ Bader charges, which is consistent across both cells. The first $\mathrm{K}_{\mathrm{Sr}}^{\prime}$ oxidizes the Fe sublattice by $0.30 e$ and the $\mathrm{O}$ sublattice by $0.43 e$, while the second $\mathrm{K}_{\mathrm{Sr}}^{\prime}$ oxidizes the Fe sublattice by $0.40 e$ and the $\mathrm{O}$ sublattice by $0.37 e$. The small remainders of 0.05 and $0.01 e$ required to make the total oxidation $0.78 e$ (vide supra) for the formation of the first and second $\mathrm{K}_{\mathrm{Sr}}^{\prime}$, respectively, are taken from the $\mathrm{Sr}$ sublattice and produce a negligible effect on the average Sr Bader charge.

From the preceding analysis, we conclude that the holes introduced by $\mathrm{K}_{\mathrm{Sr}}^{\prime}$ substitutional defects are delocalized across both $\mathrm{Fe}$ and $\mathrm{O}$ sublattices. This conclusion is consistent with 
Table II. Fe magnetic moments $\left(\mu_{\mathrm{Fe}}\right.$ in $\left.\mu_{\mathrm{B}}\right)$ and Bader charges $\left(q_{\mathrm{Fe}}, q_{\mathrm{Sr}}, q_{\mathrm{K}}\right.$, and $q_{0}$ in $e$ ) for SKFO with $x_{K}=0,0.0625$, and 0.125 .

\begin{tabular}{llll}
\hline & $x_{\mathrm{K}}=0$ & $x_{\mathrm{K}}=0.0625$ & $x_{\mathrm{K}}=0.125$ \\
\hline$\mu_{\mathrm{Fe}}$ & $2.86-2.87$ & 2.80 & $2.83-2.84$ \\
\hline$q_{\mathrm{Fe}}$ & 1.55 & $1.57 \pm 0.02$ & $1.60 \pm 0.02$ \\
\hline$q_{\mathrm{Sr}}$ & 1.60 & 1.60 & 1.60 \\
\hline$q_{\mathrm{K}}$ & - & 0.82 & 0.82 \\
\hline$q_{0}$ & -1.05 & -1.04 & $-1.03 \pm 0.01$ \\
\hline
\end{tabular}

the presented PDOS (Fig. 2), which show significant hybridization between the $\mathrm{O} 2 p$ and $\mathrm{Fe} 3 d$ states.

The motivation for choosing SKFO over $\mathrm{SrFeO}_{3}$ is that the introduction of holes should lower the $\mathrm{V}_{\mathrm{O}}^{\bullet \bullet}$ formation energy by promoting reduction of the lattice, leading to higher $\mathrm{V}_{\mathrm{O}}^{\bullet \bullet}$ concentrations and improved oxide-ion diffusivity. However, we must determine whether or not this hypothesis holds. If so, to what extent do the holes from $\mathrm{K}_{\mathrm{Sr}}^{/}$reduce the $\mathrm{V}_{\mathrm{O}}^{\bullet \bullet}$ formation energy $\left(\Delta E_{\mathrm{f}, \mathrm{vac}}\right)$ ? We address these questions by computing the $\Delta E_{\mathrm{f} \text {,vac }}$ in the 80 -atom supercell (Fig. 1) with one $\mathrm{K}_{\mathrm{Sr}}^{\prime}$ present. Whenever two defects (e.g., one $\mathrm{K}_{\mathrm{Sr}}^{/}$and one $\mathrm{V}_{\mathrm{O}}^{\bullet \bullet}$ ) are present, the proximity of these defects may impact the defect formation energies. However, our previous discussion of $\mathrm{K}_{\mathrm{Sr}}^{/}$defects (vide supra) that produce delocalized positive charge in the lattice suggests that proximity between defects will have a negligible effect on $\Delta E_{\mathrm{f} \text {,vac }}$.

$\mathrm{V}_{\mathrm{O}}^{\bullet \bullet}$ formation in SKFO is governed by Eq. (3), where $\delta$ corresponds to one $\mathrm{V}_{\mathrm{O}}^{\bullet \bullet}$ being formed in the 80-atom supercell. This leads to the expression for $\Delta E_{\mathrm{f}, \mathrm{vac}}$ given in Eq. (4).

$$
\begin{gathered}
\mathrm{Sr}_{1-x} \mathrm{~K}_{x} \mathrm{FeO}_{3} \rightarrow \mathrm{Sr}_{1-x} \mathrm{~K}_{x} \mathrm{FeO}_{3-\delta}+\left(\frac{1}{2}\right) \mathrm{O}_{2}(\mathrm{~g}), \\
\Delta E_{\mathrm{f}, \mathrm{vac}}=E_{\text {defective }}+\left(\frac{1}{2}\right) E_{\mathrm{O}_{2}}-E_{\text {host }} .
\end{gathered}
$$

In Eq. (4), $E_{\text {defective }}$ is the energy of the supercell with a $\mathrm{V}_{\mathrm{O}}^{\bullet \bullet}$ present, $E_{\mathrm{O}_{2}}$ is the energy of the isolated oxygen molecule, and $E_{\text {host }}$ is the energy of the supercell without a $\mathrm{V}_{\mathrm{O}}^{\bullet \bullet}$ defect. The thermal contributions, both enthalpic and entropic, from the host and defective solids are expected to be comparable and therefore can be neglected (e.g., we computed the thermal contribution to $\Delta G_{\mathrm{f}, \mathrm{vac}}$ from the solids to be only $0.02 \mathrm{eV}$ at $700{ }^{\circ} \mathrm{C}$ in $\left.\mathrm{LaFeO}_{3}\right) .{ }^{[20,21]} \mathrm{We}$ include thermal contributions from the $\mathrm{O}_{2}$ molecule because they contribute significantly at SOFC operating temperatures. ${ }^{[20,21]}$ While the free energy $\left(\Delta G_{f, v a c}\right)$ governs the $\mathrm{V}_{\mathrm{O}}^{\bullet \bullet}$ concentration, our assumption about the negligible thermal contributions means that trends in $\Delta E_{\mathrm{f}, \mathrm{vac}}$ should mirror those in $\Delta G_{\mathrm{f}, \mathrm{vac}}$.

The $\mathrm{V}_{\mathrm{O}}^{\bullet \bullet}$ formation energies for various $\mathrm{K}_{\mathrm{Sr}}^{/}-\mathrm{V}_{\mathrm{O}}^{\bullet \bullet}$ distances are presented in Table III. The data confirm our expectation
Table III. Uncorrected $\mathrm{V}_{\mathrm{O}}^{\bullet \bullet}$ formation energies $\left(\Delta E_{\mathrm{f}, \mathrm{vac}}\right.$ in $\left.\mathrm{eV}\right)$ and free energies $\left[\Delta G_{\mathrm{f}, \text { vac }}\left(700^{\circ} \mathrm{C}\right)\right.$ in $\left.\mathrm{eV}\right]$ in $\mathrm{Sr}_{0.9375} \mathrm{~K}_{0.0625} \mathrm{FeO}_{3}$ as a function of $\mathrm{K}_{\mathrm{Sr}}^{\prime}-\mathrm{V}_{\mathrm{O}}^{\bullet}$ separation $\left(d_{\mathrm{K}_{\mathrm{Sr}}^{\prime}}-\mathrm{v}_{\mathrm{o}}\right.$. in $\AA$ ). Corrected $\Delta E_{\mathrm{f}, \mathrm{vac}}$ and $\Delta G_{\mathrm{f}, \text { vac }}$ values are reported in parentheses (corrected for the DFT-GGA error for $\mathrm{O}_{2}$ ). $\Delta E_{\mathrm{f}, \mathrm{vac}}$ is 1.27 (1.69) $\mathrm{eV}$ for $\mathrm{SrFeO}_{3}$ in the same supercell.

\begin{tabular}{lll}
\hline$d_{\mathrm{K}_{\mathrm{Sr}}^{\prime}-\mathrm{v}_{\mathrm{o}}}$ & $\Delta E_{\mathrm{f}, \mathrm{vac}}$ & $\Delta G_{\mathrm{f}, \mathrm{vac}}\left(700^{\circ} \mathrm{C}\right)$ \\
\hline 2.77 & $1.07(1.49)$ & $0.05(0.47)$ \\
\hline 4.71 & $1.07(1.49)$ & $0.05(0.47)$ \\
\hline 6.08 & $1.13(1.55)$ & $0.10(0.52)$ \\
\hline
\end{tabular}

that there is no significant effect from the proximity of the two defects. This result is consistent with the metallic nature of $\mathrm{SKFO}$. The $\mathrm{V}_{\mathrm{O}}^{\bullet \bullet}$ formation energies are computed using the optimized geometries containing both the $\mathrm{K}_{\mathrm{Sr}}^{\prime}$ and $\mathrm{V}_{\mathrm{O}}^{\bullet \bullet}$ defects.

The uncorrected $\Delta E_{\mathrm{f} \text {,vac }}$ values in Table III (1.07-1.13 eV) must then be compared with the uncorrected $\Delta E_{\mathrm{f}, \mathrm{vac}}$ value $(1.27 \mathrm{eV})$ obtained in the same supercell in the absence of $\mathrm{K}_{\mathrm{Sr}}^{\prime}$. This decrease in $\Delta E_{\mathrm{f} \text {,vac }}(\sim 0.2 \mathrm{eV})$ indicates that the $\mathrm{V}_{\mathrm{O}}^{\bullet \bullet}$ formation is made easier by charge compensation. The $\Delta G_{\mathrm{f} \text {,vac }}$ values computed without the $\mathrm{O}_{2}$ bond dissociation energy correction indicate that our chosen $\mathrm{V}_{\mathrm{O}}^{\bullet \bullet}$ concentration $(\delta=$ $0.0625)$ is close to the expected concentration. However, the corrected values are positive, indicating that we should predict a $\mathrm{V}_{\mathrm{O}}^{\bullet \bullet}$ concentration for $x_{\mathrm{K}}=0.0625$ far lower than the concentration we employed. This effect must be balanced against the fact that larger $x_{\mathrm{K}}$ concentrations (e.g., $x_{\mathrm{K}}=0.125$ ) not considered here contain far more holes and may lead to lower $\Delta G_{\mathrm{f}, \mathrm{vac}}$ values. The limitation of our preliminary study is that we have only investigated the scenario where $x_{\mathrm{K}}$ and $\delta$ are equal to one another. The material, as synthesized by Hou et al., has $\delta=0.20$ at $800{ }^{\circ} \mathrm{C} .{ }^{[9]}$ Exploring different ratios of $\mathrm{K}_{\mathrm{Sr}}^{\prime}$-to- $\mathrm{V}_{\mathrm{O}}^{\bullet \bullet}$ is beyond the scope of this work; however, such an investigation should yield insight into the $\mathrm{V}_{\mathrm{O}}^{\bullet \bullet}$ formation process when more holes are present in the supercell.

The preceding analysis has successfully answered the questions we posed at the start of this work. We find that potassium substitution is endothermic in SKFO raising questions about the long-term stability of this material for use in SOFC applications. Endothermic $\mathrm{K}_{\mathrm{Sr}}^{\prime}$ substitutions may lead to phase instability at lower operating temperatures where the entropic driving force associated with producing $\mathrm{O}_{2}(\mathrm{~g})$ does not outweigh the energetic cost of forming the substitutional defect. Experimentalists should determine whether the endothermicity of these substitutions necessitates high-temperature SOFC operation. Our oxygen vacancy formation energies differ from previous studies of electron-deficient substitutions (e.g., $\mathrm{Sr}^{2+}$ for $\mathrm{La}^{3+}$ in $\left.\mathrm{La}_{1-x} \mathrm{Sr}_{x} \mathrm{FeO}_{3-\delta}\right)^{[20]}$ in related materials. Specifically, the charge compensation effect in $\mathrm{La}_{1-x} \mathrm{Sr}_{x}$ $\mathrm{FeO}_{3-\delta}$ leads to dramatic drop of $\sim 3.5 \mathrm{eV}$ in $\Delta G_{\text {f,vac }}$ when increasing $x_{\mathrm{Sr}}$ from 0 to 0.25 . In contrast, we find only a small 
decrease of $\sim 0.2 \mathrm{eV}$ for $\Delta G_{\text {f,vac }}$ in SKFO when $x_{\mathrm{K}}$ is increased from 0 to 0.0625 . Charge compensation between holes introduced by $\mathrm{Sr}$ substitution and oxygen vacancies in $\mathrm{La}_{1-x} \mathrm{Sr}_{x}$ $\mathrm{FeO}_{3-\delta}$ enables the $\mathrm{Fe}$ ions to retain their $\mathrm{Fe}^{3+}$ (high spin $d^{5}$ ) configuration. $^{[20]}$ The same effect in SKFO plays a smaller role $(\sim 0.2 \mathrm{eV})$ because the holes are delocalized (vide supra) and the $\mathrm{Fe}$ ions remain trapped between the $3+$ and the (less stable) $4+$ oxidation states.

We have presented a DFT-based analysis of SKFO $\left(x_{\mathrm{K}}=0\right.$, 0.0625 , and 0.125 ). Potassium substitutions introduce more $\mathrm{Fe}^{4+}$ ions by oxidizing the $\mathrm{Fe}$ sublattice. However, these substitutions are endothermic, suggesting that SKFO may be unstable at the desired lower operating temperatures. The presence of potassium in SKFO is predicted to lower the oxygen vacancy formation energy by $\sim 0.20 \mathrm{eV}$, leading to the expectation of somewhat higher oxygen vacancy concentrations and improved oxygen ion conductivity compared to $\mathrm{SrFeO}_{3}$. This increase in the oxygen vacancy concentration comes without substantial alterations in the electronic structure when SKFO and $\mathrm{SrFeO}_{3}$ are compared. Further study of this material will determine its suitability for SOFC applications and may lead to improved SOFC devices.

\section{Supplementary material}

The supplementary material for this article can be found at http://dx.doi.org/10.1557/mrc.2016.23.

\section{Acknowledgments}

We thank Michele Pavone, Ana Belen Muñoz-García, and John Keith for helpful discussions in the course of this study. We thank Nari Baughman for help in revising this Communication. HeteroFoaM, an Energy Frontier Research Center funded by the US Department of Energy, Office of Science, Office of Basic Energy Sciences, under the award DE-SC0001061 provided funding for this work. The simulations carried out in this work were performed on computational resources supported by the Princeton Institute for Computational Science and Engineering (PICSciE) and the Office of Information Technology's High Performance Computing Center at Princeton University.

\section{References}

1. N.Q. Minh: Ceramic fuel cells. J. Am. Ceram. Soc. 76, 563 (1993).

2. B.C.H. Steele and A. Heinzel: Materials for fuel-cell technologies. Nature 414, 345 (2001).

3. Z. Lu, J. Hardy, J. Templeton, and J. Stevenson: Extended reaction zone of $\mathrm{La}_{0.6} \mathrm{Sr}_{0.4} \mathrm{Co}_{0.2} \mathrm{Fe}_{0.8} \mathrm{O}_{3}$ cathode for solid oxide fuel cell. J. Power Sources 198, 90 (2012).

4. M. Gödickemeier, K. Sasaki, L.J. Gauckler, and I. Riess: Perovskite cathodes for solid oxide fuel cells based on ceria electrolytes. Solid State Ion. 86-88(Part 2), 691 (1996).

5. D. Marinha, L. Dessemond, J.S. Cronin, J.R. Wilson, S.A. Barnett, and E. Djurado: Microstructural 3D reconstruction and performance evaluation of LSCF cathodes obtained by electrostatic spray deposition. Chem. Mater. 23, 5340 (2011).
6. D. Rembelski, J.P. Viricelle, L. Combemale, and M. Rieu: Characterization and comparison of different cathode materials for SC-SOFC: LSM, BSCF, SSC, and LSCF. Fuel Cells 12, 256 (2012).

7. Y. Li, K. Gerdes, T. Horita, and X. Liu: Surface exchange and bulk diffusivity of LSCF as SOFC cathode: electrical conductivity relaxation and isotope exchange characterizations. J. Electrochem. Soc. 160, F343 (2013).

8. Z. Shao, W. Yang, Y. Cong, H. Dong, J. Tong, and G. Xiong: Investigation of the permeation behavior and stability of a $\mathrm{Ba}_{0.5} \mathrm{Sr}_{0.5} \mathrm{CO}_{0.8} \mathrm{Fe}_{0.2} \mathrm{O}_{3-\delta}$ oxygen membrane. J. Membr. Sci. 172, 177 (2000).

9. S. Hou, J.A. Alonso, and J.B. Goodenough: Co-free, iron perovskites as cathode materials for intermediate-temperature solid oxide fuel cells. J. Power Sources 195, 280 (2010).

10. Q. Liu, X. Dong, G. Xiao, F. Zhao, and F. Chen: A novel electrode material for symmetrical SOFCs. Adv. Mater. 22, 5478 (2010).

11. J.-J. Choi, W. Qin, M. Liu, and M. Liu: Preparation and characterization of $\left(\mathrm{La}_{0.8} \mathrm{Sr}_{0.2}\right)_{0.95} \mathrm{MnO}_{3-\delta}(\mathrm{LSM})$ thin films and LSM/LSCF interface for solid oxide fuel cells. J. Am. Ceram. Soc. 94, 3340 (2011).

12. C. Endler-Schuck, J. Joos, C. Niedrig, A. Weber, and E. Ivers-Tiffée: The chemical oxygen surface exchange and bulk diffusion coefficient determined by impedance spectroscopy of porous $\mathrm{La}_{0.58} \mathrm{Sr}_{0.4} \mathrm{Co}_{0.2} \mathrm{Fe}_{0.8} \mathrm{O}_{3-\delta}$ (LSCF) cathodes. Solid State Ion. 269, 67 (2015).

13. B. Fan and X. Liu: A-deficit LSCF for intermediate temperature solid oxide fuel cells. Solid State Ion. 180, 973 (2009).

14. S. Hou, J.A. Alonso, S. Rajasekhara, M.J. Martínez-Lope, M.T. FernándezDíaz, and J.B. Goodenough: Defective Ni perovskites as cathode materials in intermediate-temperature solid-oxide fuel cells: a structure-properties correlation. Chem. Mater. 22, 1071 (2010).

15. S. Hou, A. Aguadero, J.A. Alonso, and J.B. Goodenough: Fe-based perovskites as electrodes for intermediate-temperature solid oxide fuel cells. J. Power Sources 196, 5478 (2011).

16. J.F. Monteiro, J.C. Waerenborgh, A.V. Kovalevsky, A.A. Yaremchenko, and J.R. Frade: Synthesis of $\mathrm{Sr}_{0.9} \mathrm{~K}_{0.1} \mathrm{FeO}_{3-\delta}$ electrocatalysts by mechanical activation. J. Solid State Chem. 198, 169 (2013).

17. M. Pavone, A.M. Ritzmann, and E.A. Carter: Quantum-mechanics-based design principles for solid oxide fuel cell cathode materials. Energy Environ. Sci. 4, 4933 (2011).

18. E.A. Kotomin, Y.A. Mastrikov, M.M. Kuklja, R. Merkle, A. Roytburd, and J. Maier: First principles calculations of oxygen vacancy formation and migration in mixed conducting $\mathrm{Ba}_{0.5} \mathrm{Sr}_{0.5} \mathrm{CO}_{1-y} \mathrm{Fe}_{y} \mathrm{O}_{3-\delta}$ perovskites. Solid State Ion. 188, 1 (2011).

19. A.B. Muñoz-García, D.E. Bugaris, M. Pavone, J.P. Hodges, A. Huq, F. Chen, H.-C. zur Loye, and E.A. Carter: Unveiling structure-property relationships in $\mathrm{Sr}_{2} \mathrm{Fe}_{1.5} \mathrm{Mo}_{0.5} \mathrm{O}_{6-\delta}$, an electrode material for symmetric solid oxide fuel cells. J. Am. Chem. Soc. 134, 6826 (2012).

20. A.M. Ritzmann, A.B. Muñoz-García, M. Pavone, J.A. Keith, and E.A. Carter: $A b$ initio $D F T+U$ analysis of oxygen vacancy formation and migration in $\mathrm{La}_{1-x} \mathrm{Sr}_{x} \mathrm{FeO}_{3-\delta}(x=0,0.25,0.50)$. Chem. Mater. 25, 3011 (2013).

21. A.M. Ritzmann, A.B. Muñoz-García, M. Pavone, J.A. Keith, and E. A. Carter: $\mathrm{Ab}$ initio evaluation of oxygen diffusivity in $\mathrm{LaFeO}_{3}$ : the role of lanthanum vacancies. MRS Commun. 3, 161 (2013).

22. Y.A. Mastrikov, R. Merkle, E.A. Kotomin, M.M. Kuklja, and J. Maier: Formation and migration of oxygen vacancies in $\mathrm{La}_{1-x} \mathrm{Sr}_{x} \mathrm{C}_{1-y} \mathrm{Fe}_{y} \mathrm{O}_{3-\delta}$ perovskites: insight from ab initio calculations and comparison with $\mathrm{Ba}_{1-x} \mathrm{Sr}_{x} \mathrm{CO}_{1-y} \mathrm{Fe}_{y} \mathrm{O}_{3-\delta}$. Phys. Chem. Chem. Phys. 15, 911 (2013).

23. M.M. Kuklja, E.A. Kotomin, R. Merkle, Y.A. Mastrikov, and J. Maier: Combined theoretical and experimental analysis of processes determining cathode performance in solid oxide fuel cells. Phys. Chem. Chem. Phys. 15, 5443 (2013).

24. A.B. Muñoz-García, A.M. Ritzmann, M. Pavone, J.A. Keith, and E. A. Carter: Oxygen transport in perovskite-type solid oxide fuel cell materials: insights from quantum mechanics. Acc. Chem. Res. 47, 3340 (2014).

25. D. Gryaznov, S. Baumann, E.A. Kotomin, and R. Merkle: Comparison of permeation measurements and hybrid density-functional calculations on oxygen vacancy transport in complex perovskite oxides. J. Phys. Chem. C 118, 29542 (2014).

26. A.M. Ritzmann, J.M. Dieterich, and E.A. Carter: Density functional theory + $\mathrm{U}$ analysis of the electronic structure and defect chemistry of LSCF $\left(\mathrm{La}_{0.5} \mathrm{Sr}_{0.5} \mathrm{Co}_{0.25} \mathrm{Fe}_{0.75} \mathrm{O}_{3-\delta}\right)$. Phys. Chem. Chem. Phys. 18, 12260 (2016). 
27. F.A. Kröger and H.J. Vink: Relations between the concentrations of imperfections in crystalline solids. In Solid State Physics, vol. 3, edited by F. Seitz and D. Turnbull (Academic Press: New York, 1956), p. 307.

28. G. Kresse and J. Hafner: Ab initio molecular dynamics for open-shell transition metals. Phys. Rev. B 48, 13115 (1993).

29. J.P. Perdew, K. Burke, and M. Ernzerhof: Generalized gradient approximation made simple. Phys. Rev. Lett. 77, 3865 (1996).

30. K. Momma and F. Izumi: VESTA 3 for three-dimensional visualization of crystal, volumetric and morphology data. J. Appl. Crystallogr. 44, 1272 (2011). 